\title{
Low dose intrathecal morphine facilitates early extubation after cardiac surgery: results of a retro- spective continuous quality improvement audit
}

\author{
[L'administration intrathécale d'une faible dose de morphine facilite l'extubation précoce après
}

la cardiochirurgie : résultats d'un audit rétrospectif continu sur l'amélioration de la qualité]

Joel L. Parlow MD FrCPC MSc, R. Geoffrey Steele mbbs FAnZCA MRCA, Deirdre O'Reilly BPHARM MSc

Purpose: To document one centre's experience with a multimodal analgesic approach, with or without low dose intrathecal morphine (ITM), in facilitating "fast-track" recovery in patients undergoing cardiac surgery.

Methods: Records of 131 consecutive patients who underwent first time elective cardiac surgery during a four-month period in 2000 were reviewed. Patients were divided into two groups: those receiving and those not receiving preoperative low dose ITM $(<5$ $\left.\mu g \cdot \mathrm{kg}^{-1}\right)$ as part of a multimodal analgesic technique. Demographic and surgical characteristics, postoperative morphine use, time to extubation and requirement for antiemetics were recorded.

Results: Overall, $75 \%$ of patients were extubated within two hours, and 93\% within six hours. Fifty-five patients received, and 76 did not receive, ITM (mean \pm SD $259 \pm 53 \mu \mathrm{g}$ ) along with a multimodal analgesic technique (parasternal infiltration, acetaminophen and indomethacin, and postoperative iv morphine). Anesthetic technique involved modest dose opioids, volatile agent and propofol infusion. The groups were similar with respect to preoperative, intraoperative and anesthetic characteristics.

Mean extubation time for fast-track patients receiving vs not receiving ITM was $75 \pm 65$ vs $117 \pm 85 \mathrm{~min}(P=0.003)$. Intravenous morphine use for the first $12 \mathrm{hr}$ after surgery was also reduced in the ITM group $(4.6 \pm 4.1$ vs $10.0 \pm 14.8 \mathrm{mg}, P=0.009)$. There was no difference in rescue antiemetic or antipruritic requirements, failed fast-tracking, or serious adverse events.

Conclusions: Multimodal postoperative analgesia allowed for uneventful early extubation and low opioid requirements. Low dose ITM further facilitated early extubation, and reduced postoperative analgesic requirements.
Objectif ${ }^{n}$ : Documenter l'expérimentation d'une approche analgésique multimodale, comportant ou non une faible dose de morphine intrathécale (MIT), visant à faciliter la récupération rapide chez les patients de cardiochirurgie.

Méthode: Nous avons revu les dossiers de 13 I patients consécutifs qui ont subi une première intervention cardiaque réglée au cours de quatre mois en 2000. Les patients ont reçu ou non une faible dose de MIT préopératoire $\left(<5 \mu \mathrm{g} \cdot \mathrm{kg}^{-1}\right)$ dans le cadre d'une analgésie multimodale. Les caractéristiques démographiques et chirurgicales, l'utilisation de morphine postopératoire, le temps écoulé avant l'extubation et la demande d'antiémétique ont été notés.

Résultats : Globalement, deux heures après l'opération $75 \%$ des patients étaient extubés et $93 \%$ six heures après. Cinquante-cinq patients ont reçu, et 76 n'ont pas reçu, de MIT (259 $\pm 53 \mu \mathrm{g}$, moyenne \pm écart type) avec une technique analgésique multimodale (infiltration parasternale, acétaminophène et indométacine, et morphine iv postopératoire). La technique anesthésique comportait de faibles doses d'opioïdes, un agent volatil et une perfusion de propofol. Les groupes étaient similaires quant aux caractéristiques préopératoires, peropératoires et anesthésiques. Le temps moyen avant l'extubation pour les patients avec ou sans MIT a été de $75 \pm 65$ vs $1 / 7$ $\pm 85 \mathrm{~min}(P=0,003)$. L'usage de morphine intraveineuse pendant les 12 premières heures postopératoires a aussi été réduit dans le groupe qui a reçu la MIT (4,6 \pm 4, I vs 10,0 \pm 14,8 mg, $P=0,009)$. Aucune différence intergroupe n'est apparue pour les demandes d'antiémétiques ou d'antipruritiques de secours, l'échec de l'extubation précoce ou le nombre d'événements indésirables sérieux.

Conclusion : L'analgésie postopératoire multimodale permet une extubation précoce sans incident et un faible recours aux opioïdes. Une faible dose de MIT facilite davantage l'extubation précoce et réduit les demandes d'analgésiques postopératoires.

From the Department of Anesthesiology, Queen's University and Kingston General Hospital, Kingston, Ontario, Canada. Address correspondence to: Dr. Joel Parlow, Department of Anesthesiology, Kingston General Hospital, 76 Stuart Street, Kingston,

Ontario K7L 2V7, Canada. Phone: 613-548-7827; Fax: 613-548-1375; E-mail: parlowj@post.queensu.ca

This project was funded using internal institutional support. No potential conflicts of interest. Accepted for publication November 21, 2003.

Revision accepted September 10, 2004. 


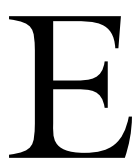

ARLY extubation is an integral part of comprehensive "fast-track" techniques, which aim to shorten intensive care unit stays and reduce perioperative costs and resource utilization following cardiac surgery. ${ }^{1,2}$ Inherent in most early extubation strategies is the use of short acting anesthetic drugs, coupled with effective postoperative analgesia. At our institution, we have adopted an early extubation strategy which includes low doses of intraoperative opioids, and a multimodal postoperative analgesic regimen. This consists of a combination of local anesthetic infiltration at the sternum and drain sites, adjuvant analgesics, postoperative iv opioids on demand, with or without a single injection of low dose intrathecal morphine (ITM) preoperatively. Patients are cared for postoperatively in a dedicated cardiovascular surgical intensive care unit (CVICU) under the care of an attending anesthesiologist. Optimally, patients are extubated within the first two hours following completion of surgery; for the purpose of this study, successful early extubation is arbitrarily defined as extubation within six hours of surgery.

ITM produces effective analgesia in patients undergoing cardiac surgery and can be used as part of a multimodal approach to analgesia for cardiac surgery. ${ }^{3}$ However, when used in large doses ${ }^{3,4}$ and moderate doses $\left(10 \mu \mathrm{g} \cdot \mathrm{kg}^{-1}\right)^{5}$ ITM leads to delayed extubation. Lower doses of ITM have been used effectively for analgesia following Cesarean section $(100 \mu \mathrm{g}),{ }^{6}$ hip replacement surgery $(100 \mu \mathrm{g})^{7}$ and knee replacement surgery $(300 \mu \mathrm{g}) .^{8}$ There are reports of the use of lower doses of ITM $(250 \mu \mathrm{g}$ or $500 \mu \mathrm{g})$ as part of a fast-track approach in cardiac surgery, with no effect on extubation time (six to seven hours). ${ }^{9}$

The current study was designed as a retrospective, comparative, continuous quality improvement audit. This study aimed to establish 1) the success rate for early extubation using our multimodal analgesic approach; and 2) whether the inclusion of low dose ITM $\left(<5 \mu \mathrm{g} \cdot \mathrm{kg}^{-1}\right)$ further affected extubation times or opioid requirements in the early postoperative period.

\section{Methods}

After obtaining Institutional Ethics approval, a retrospective review of in-patient records from 131 patients consecutively undergoing first time elective cardiac surgery (coronary artery bypass, single valve replacement or atrial septal defect repair) via sternotomy and cardiopulmonary bypass, during a four-month period in 2000 was undertaken. All patients had recovered in the CVICU under the care of a dedicated cardiac anesthesiologist and the attending cardiac surgeon, who were aware of all treatments, and who made all therapeutic and ventilatory decisions. Intravenous morphine was administered by nurses according to standardized orders, or by patient request or expression of pain when they were conscious. Data were collected from all charts reviewed, and successful "early extubation" was defined as extubation within six hours of arrival to the CVICU.

A database was compiled to document preoperative, intraoperative, and postoperative events. Patients who had received $v s$ those who had not received ITM as part of the multimodal analgesic routine (at the discretion of their attending anesthesiologist) were separated into two groups. Demographic information, attending physicians and surgeons, type and duration of surgery, intraoperative anesthetic drugs, use of $i v$ opioids and use of co-analgesics and antiemetics were included. Primary endpoints analyzed included time to extubation and postoperative morphine utilization. Secondary endpoints included requirements for antiemetic and antipruritic rescue drugs.

Data were analyzed using Sigmastat version 2.0 (Jandel Scientific Inc., San Rafael, CA, USA). Comparisons between the groups receiving and not receiving ITM were made using Mann-Whitney rank sum test for non-normally distributed data, and Chi square tests for incidence data. A $P$-value of less than 0.05 was defined as statistically significant.

\section{Results}

Data from 131 patients were considered, consisting of 55 patients who received ITM (ITM group), and 76 patients who did not receive ITM (No ITM group). The exact anesthetic technique, including the use of ITM, was at the discretion of the cardiac anesthesiologist, however all patients received moderate doses of opioids intraoperatively (mean $111 \pm 58 \mu \mathrm{g}$ sufentanil), low dose midazolam and isoflurane, and propofol infusion during cardiopulmonary bypass and during transport to the CVICU. Patients in the ITM group had spinal injections performed prior to induction of anesthesia, in the sitting position using a 24gauge Sprotte needle, with confirmation of free flow of cerebrospinal fluid. No bloody spinal taps were obtained, and no surgery was cancelled due to complications of intrathecal injection. Prophylactic antiemetics (ondansetron $4 \mathrm{mg} i \mathrm{v}$ ) were administered prior to extubation, which was carried out by the attending CVICU anesthesiologists and respiratory technologists according to standard criteria. The multimodal analgesic strategy included a combination of parasternal infiltration or open intercostal nerve block with local anesthetic, rectal acetaminophen and 
TABLE I Patient demographics and intraoperative characteristics

\begin{tabular}{|c|c|c|}
\hline & No ITM $(n=76)$ & $\operatorname{ITM}(n=55)$ \\
\hline $\operatorname{Age}(y r)^{*}$ & $65 \pm 96$ & $62 \pm 12$ \\
\hline Male/female (no.) & $58 / 18$ & $44 / 11$ \\
\hline Weight $(\mathrm{kg})^{*}$ & $79 \pm 14$ & $82 \pm 13$ \\
\hline Left ventricular grade $* *$ (median) & 2 & 2 \\
\hline Chronic respiratory disease (no.) & 18 & 8 \\
\hline $\mathrm{CABG} /$ valve (no.) & $63 / 13$ & $48 / 7$ \\
\hline Bypass time $(\min )^{*}$ & $82 \pm 40$ & $73 \pm 31$ \\
\hline Intraoperative sufentanil $(\mu \mathrm{g})^{*}$ & $121 \pm 69$ & $104 \pm 42$ \\
\hline Local anesthetic infiltration (no.) & 57 & 41 \\
\hline Total acetaminophen in CVICU $(\mathrm{mg}) \dagger$ & $2523 \pm 1077 ; 2600$ & $2618 \pm 920 ; 2600$ \\
\hline Total indomethacin in CVICU $(\mathrm{mg}) \dagger$ & $76 \pm 61 ; 100$ & $77 \pm 62 ; 100$ \\
\hline
\end{tabular}

${ }^{*}$ Mean $\pm \mathrm{SD}$; †mean $\pm \mathrm{SD}$; median. $P=$ ns for all variables. ${ }^{*}$ Left ventricular grade by ejection fraction $(\mathrm{EF}) \mathrm{l}: \mathrm{EF}>60 \%, 2: \mathrm{EF} 40-60 \%$, 3: $\mathrm{EF} 20-40 \%, 4: \mathrm{EF}<20 \%$. ITM = intrathecal morphine; $\mathrm{CABG}=$ cardiopulmonary bypass grafting; CVICU = cardiovascular surgical intensive care unit.

TABLE II Outcomes

\begin{tabular}{|c|c|c|c|c|c|c|}
\hline & \multicolumn{3}{|c|}{ Patients extubated within $6 \mathrm{hr}$} & \multicolumn{3}{|c|}{ All patients } \\
\hline & No ITM $(n=70)$ & $I T M(n=52)$ & $P$ & No ITM $(n=76)$ & $\operatorname{ITM}(n=55)$ & $P$ \\
\hline${ }^{*}$ Extubated < two hours $(\%)$ & 67 & 85 & 0.047 & 62 & 80 & 0.042 \\
\hline †Extubation time: Median & 92 & 56 & & 100 & 58 & \\
\hline Mean \pm SEM & $117 \pm 10$ & $75 \pm 9$ & 0.001 & $234 \pm 50$ & $146 \pm 43$ & 0.002 \\
\hline $95 \%$ confidence interval & $97-140$ & $57-93$ & & $130-330$ & $58-230$ & \\
\hline$†$ Median postop duration of hospital stay (days) & 6.0 & 5.0 & 0.079 & 6.0 & 5.0 & 0.049 \\
\hline
\end{tabular}

Extubation times in minutes from end of surgery. ITM = intrathecal morphine (mean $259 \pm 53 \mu \mathrm{g}$ ). ${ }^{*}$ Chi square; †Mann-Whitney rank sums test.

indomethacin, and postoperative iv morphine on demand. These modalities were provided at the discretion of attending physicians, irrespective of whether or not they received ITM. Patient demographic and clinical variables are shown in Table I. There were no differences between groups in any preoperative variables (age, weight, coronary disease, left ventricular function and comorbid respiratory or renal disease), intraoperative variables (anesthetic agents, total opioid dose, anesthesia time, cardiopulmonary bypass time, surgical procedures, number of coronary grafts), or in other modalities used for analgesia besides ITM (acetaminophen, indomethacin, local anesthetic infiltration).

Mean \pm SD ITM dose in the ITM group was 259 $\pm 53 \mu \mathrm{g}$, or $3.2 \pm 0.7 \mu \mathrm{g} \cdot \mathrm{kg}^{-1}$ (range $1.9-4.7 \mu \mathrm{g} \cdot \mathrm{kg}^{-1}$ ). Extubation times are shown in Table II. Overall, 75\% of patients were extubated within two hours of arrival in the CVICU, and $93 \%$ were extubated within six hours. Nine patients (three ITM, six No ITM) required prolonged intubation greater than six hours (range 15.7-44 hr), and thus did not meet "early extubation" criteria. Reintubation was required for 5 (3.8\%) patients (two ITM, three No ITM). Of the
122 early extubation patients, time to extubation was significantly shorter in ITM patients $(75 \pm 65 \mathrm{~min} v \mathrm{~s}$ $117 \pm 85 \mathrm{~min}$ for No ITM, $P=0.001$, Table II). Of this group, total postoperative hospital stay was similar between ITM and No ITM. However, when all patients were considered, ITM patients had a shorter postoperative length of hospital stay (borderline significance; Table II).

Early extubation patients in the ITM group received significantly less $i v$ morphine during the first $12 \mathrm{hr}(P<$ $0.001)$ and $24 \mathrm{hr}(P=0.017)$ postoperatively (Figure). There was no difference in need for rescue antiemetic or antipruritic medications (Table II), and no patient suffered neurological deficits as a complication of intrathecal injection and anticoagulation.

\section{Discussion}

This retrospective audit suggests that using low doses of anesthetic and opioid drugs, coupled with a multimodal postoperative analgesic regimen, can result in successful early extubation following cardiac surgery. Furthermore, patients receiving low dose ITM in addition to the analgesic regimen were extubated earlier, and required less postoperative analgesics. The present 


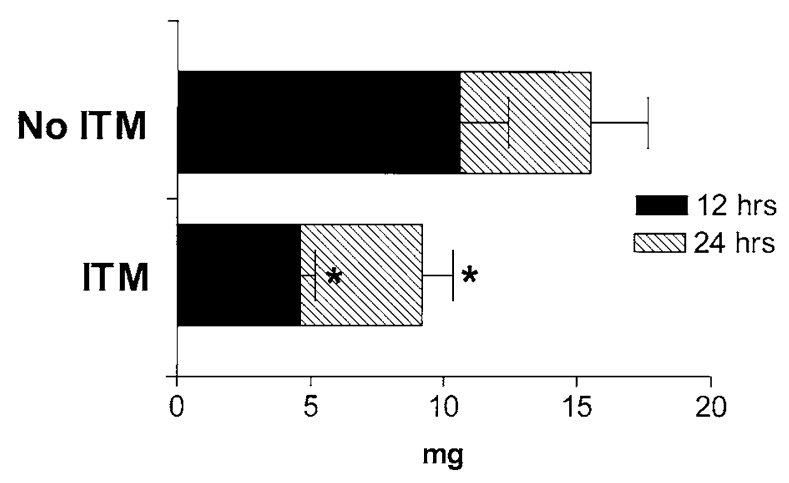

FIGURE Postoperative iv morphine (mean $\pm \mathrm{SD}$ ) requirements during the first $12 \mathrm{hr}$ period (grey sections) and second $12 \mathrm{hr}$ period (diagonal lines) postoperatively. Patients receiving multimodal analgesic techniques including preoperative intrathecal mor phine (ITM) used less morphine at $12 \mathrm{hr}(P=0.006)$ and $24 \mathrm{hr}$ $(P=0.02)$ than those not receiving ITM (No ITM). *Indicates significant difference from No ITM group.

study is novel in that it has examined actual clinical practice in a relatively large cohort of patients, demonstrating that rapid extubation (less than two hours) is feasible in a majority of patients using a simple anesthetic/analgesic strategy, and that low dose ITM facilitates this strategy without significant side effects.

Early extubation is desirable as it improves resource utilization when compared to late extubation. ${ }^{1}$ However, early extubation is most feasible when analgesia is adequate. Our study has shown that, unlike previous reports utilizing high dose intrathecal opioids, ${ }^{3}$ an early extubation strategy can be facilitated by the use of low dose ITM. Whether the further reduction in the already short duration of intubation confers clinical or economic benefit remains to be proven. In the current study, there was no difference in duration of hospital stay related to the use of ITM in the early extubation patients. However, there was a decrease in total hospital stay (borderline significance) in the ITM group when all patients were considered; this may reflect data from a small number of patients who required prolonged treatment for complications, or may be related to a periodic shortage of chronic care beds.

Postoperative iv morphine requirements were quite low in this population of patients, even in the group not receiving ITM (mean $10.6 \mathrm{mg}$ in $12 \mathrm{hr}, 15.5 \mathrm{mg}$ in $24 \mathrm{hr}$, Figure). This suggests the efficacy of the multimodal analgesic strategy, combining nonsteroidal anti-inflammatory drugs, acetaminophen and local anesthesia, although a control group not receiving these modalities was not examined. ITM further reduced parenteral morphine requirements in the first 12 and $24 \mathrm{hr}$ postsurgery, suggesting better pain control. The aggressive management of pain during the immediate postoperative period after cardiac surgery has been shown to reduce the incidence and severity of myocardial ischemia ${ }^{2}$ in adults, and the morbidity and mortality in neonates. ${ }^{10}$ It has been suggested that the administration of ITM, by improving postoperative analgesia, could improve outcome. ${ }^{3-5}$

The benefits of earlier extubation and improved pain control have not been consistently found by other researchers. A prospective randomized doubleblind study comparing placebo, $250 \mu \mathrm{g}$ and $500 \mu \mathrm{g}$ of ITM in 50 patients demonstrated decreased postoperative morphine requirements in the intrathecal group but no differences in extubation time. ${ }^{9}$ In a prospective, randomized, double-blind study of 40 patients comparing placebo to $10 \mu \mathrm{g} \cdot \mathrm{kg}^{-1}$ of ITM, no benefit was reported for postoperative morphine requirements or time to extubation. ${ }^{4}$ In addition to the higher ITM dose used in that study, patients received intraoperative iv fentanyl, $10 \mu \mathrm{g} \cdot \mathrm{kg}^{-1}$. Furthermore, cardiopulmonary bypass times ranged from $66.4 \pm$ $22.0 \mathrm{~min}$ to $101.8 \pm 22.8 \mathrm{~min}$ and extubation times ranged from five to seven hours. In the current study, extubation times were considerably less (median 77.5 $\min )$, intraoperative opioid consisted of sufentanil (mean $1.4 \mu \mathrm{g} \mathrm{kg}^{-1}$ ), and cardiopulmonary bypass times were similar to or shorter than in the previous studies.

Another approach utilized a combination of morphine, $500 \mu \mathrm{g}$, and sufentanil, $50 \mu \mathrm{g}$, given intrathecally prior to induction. ${ }^{11}$ No other opioids were used intraoperatively, and postoperative opioid requirements were low. However, that retrospective study examined the charts of only ten patients, without a cohort not receiving ITM, and mean extubation time was $6.3 \pm 1.4 \mathrm{hr}$. Investigators have also studied the use of ultra-short acting opioids in conjunction with ITM. Remifentanil combined with a large dose $(2 \mathrm{mg})$ of ITM led to a significant reduction in time to extubation (mean 156 vs $258 \mathrm{~min}$ ) and postoperative morphine requirements, when compared with iv fentanyl $12 \mu \mathrm{g} \cdot \mathrm{kg}^{-1}$ intraoperatively. ${ }^{12}$ However in another study, remifentanil with ITM $8 \mu \mathrm{g} \cdot \mathrm{kg}^{-1}$ and desflurane conferred no benefit over sufentanil and desflurane (extubation time 5.1 vs $5.8 \mathrm{hr}$ ). ${ }^{13}$ Thus it is likely that other factors, such as intraoperative opioid dose and postoperative ventilatory management, may play a more significant role in determining extubation time than simply the presence or absence of ITM. 
Retrospective studies inherently have a number of limitations. Anesthetic technique and indications for extubation were left to the individual physicians, and nursing and medical personnel were not blinded to the use of ITM. Thus a bias toward earlier fitness for extubation or reduced $i v$ morphine administration in the ITM group is quite possible. As a result, between-group comparisons made of data from this, or any retrospective study, must be viewed with these limitations in mind. In addition, other endpoints of pain control, such as visual analogue scales or satisfaction indices, would be included in prospectively designed trials, and would provide more information than morphine usage alone. On the other hand, prospective studies are by nature somewhat artificial, whereas the present study has the benefit of being clinically based, providing a "real life" measure of quality of care of the current practice within our institution.

Although no patients included in our study, or the other referenced literature, suffered adverse events attributable to intrathecal puncture, it is recognized that a theoretical risk exists of serious complications in anticoagulated patients. ${ }^{14,15}$ The risk of developing a subarachnoid or epidural hematoma may be as high as $0.35 \%,{ }^{15}$ although others report using the technique in over 3,400 patients without incident. ${ }^{16}$ It has been suggested that the time from lumbar puncture to systemic anticoagulation with heparin should exceed 60 $\min ^{14,16}$ (as in all cases in the present study), and that surgery be delayed in the event of a bloody spinal tap ${ }^{15}$ (none reported in the current study).

The relatively low dose of ITM used in this study may have resulted in the low incidence of side effects attributable to the morphine itself. Although prophylactic ondansetron was used, rescue antiemetic therapy was required in 48 of the 122 successful fast-track patients, with no difference between the groups. In addition there was no statistical difference between the groups in use of antipruritics, suggesting that low dose ITM did not increase the incidence of nausea, vomiting or pruritus. ITM can also produce dose dependent delayed respiratory depression. ${ }^{13,17}$ In a large study of 5,969 patients receiving intrathecal opioids, a $3 \%$ incidence of delayed respiratory depression was reported, none of which was life-threatening. ${ }^{18}$ Nevertheless case reports of respiratory depression with relatively low doses of ITM exist, particularly involving elderly patients. ${ }^{19}$ These risks are minimized by the close monitoring situation following cardiac surgery.

The ideal dose of ITM for cardiac surgery is not clear. In our study the mean dose was $259 \pm 53 \mu \mathrm{g}$.

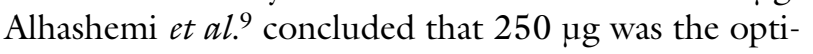
mal dose to reduce postoperative morphine require- ments without delaying extubation, while Chaney et $a l .^{5}$ used $10 \mu \mathrm{g} \cdot \mathrm{kg}^{-1}$ of ITM without benefit. Dose finding studies in gynecology ${ }^{20}$ and orthopedics ${ }^{8}$ suggest $300 \mu \mathrm{g}$ of ITM to be efficacious and safe, while Palmer ${ }^{6}$ showed $100 \mu \mathrm{g}$ to be effective for analgesia after Cesarean section. Whether even lower doses of ITM in cardiac surgery would remain effective while reducing side effects is unclear.

The current study has confirmed that a "fast-track" technique, utilizing low anesthetic and opioid doses in combination with a multimodal postoperative analgesic regimen, can result in rapid extubation following cardiac surgery. Low dose ITM facilitated this technique, further reducing the duration of intubation, and reducing postoperative opioid requirements. Our results support the consideration of future research in this field, including a prospective large scale trial investigating the potential for ITM to alter clinical or economic outcome, and to determine whether specific subgroups of this population may particularly benefit from these techniques.

\section{Acknowledgements}

The authors thank the staff of the medical records department, Kingston General Hospital, Drs. G. Ropchan, A. Hamilton and D. Petsikas, and Deborah Tod RN, for their assistance with this study.

\section{References}

1 Cheng DC, Karski J, Peniston C, et al. Early tracheal extubation after coronary artery bypass graft surgery reduces costs and improves resources use. A prospective, randomized, controlled trial. Anesthesiology 1996; 85: 1300-10.

2 Mangano DT, Siliciano D, Hollenberg $M$, et al. Postoperative myocardial ischemia. Therapeutic trials using intensive analgesia following surgery. Anesthesiology 1992; 76: 342-53.

3 Chaney MA, Smith KR, Barclay JC, Slogoff S. Largedose intrathecal morphine for coronary artery bypass grafting. Anesth Analg 1996; 83: 215-22.

4 Fitzpatrick GJ, Moriarty DC. Intrathecal morphine in the management of pain following cardiac surgery. A comparison with morphine i.v. Br J Anaesth 1988; 60: 639-44.

5 Chaney MA, Nikolov MP, Blakeman BP, Bakhos $M$. Intrathecal morphine for coronary artery bypass graft procedure and early extubation revisited. J Cardiothorac Vasc Anesth 1999; 13: 574-8.

6 Palmer CM, Emerson S, Volgoropolous D, Alves D. Dose-response relationship of intrathecal morphine for postcesarean analgesia. Anesthesiology 1999; 90: 437-44. 
7 Slappendel R, Weber EW, Dirksen R, et al. Optimization of the dose of intrathecal morphine in total hip surgery: a dose-finding study. Anesth Analg 1999; 88: 822-6.

8 Cole PJ, Craske DA, Wheatley RG. Efficacy and respiratory effects of low-dose spinal morphine for postoperative analgesia following knee arthroplasty. $\mathrm{Br} \mathrm{J}$ Anaesth 2000; 85: 233-7.

9 Alhashemi JA, Sharpe MD, Harris CL, Sherman V, Boyd $D$. Effect of subarachnoid morphine administration on extubation time after coronary artery bypass graft surgery. J Cardiothorac Vasc Anesth 2000; 14: 639-44.

10 Anand KJ, Hickey PR. Halothane-morphine compared with high-dose sufentanil for anesthesia and postoperative analgesia in neonatal cardiac surgery. $\mathrm{N}$ Engl J Med 1992; 326: 1-9.

11 Swenson JD, Hullander RM, Wingler K, Leivers D. Early extubation after cardiac surgery using combined intrathecal sufentanil and morphine. J Cardiothorac Vasc Anesth 1994; 8: 509-14.

12 Bowler I, Djaiani G, Abel R, Pugh S, Dunne J, Hall J. A combination of intrathecal morphine and remifentanil anesthesia for fast-track cardiac anesthesia and surgery. J Cardiothorac Vasc Anesth 2002; 16: 709-14.

13 Latham P, Zarate E, White PF, et al. Fast-track cardiac anesthesia: a comparison of remifentanil plus intrathecal morphine with sufentanil in a desflurane-based anesthetic. J Cardiothorac Vasc Anesth 2000; 14: 645-51.

14 Chaney MA. Side effects of intrathecal and epidural opioids. Can J Anaesth 1995; 42: 891-903.

15 Owens EL, Kasten GW, Hessel EA. Spinal subarachnoid hematoma after lumbar puncture and heparinization: a case report, review of the literature, and discussion of anesthetic implications. Anesth Analg 1986; 65:

1201-7.

16 Vandermeulen EP, Van Aken H, Vermylen J. Anticoagulants and spinal-epidural anesthesia. Anesth Analg 1994; 79: 1165-77.

17 Bailey PL, Rhondeau S, Schafer PG, et al. Doseresponse pharmacology of intrathecal morphine in human volunteers. Anesthesiology 1993; 79: 49-59.

18 Gwirtz KH, Young JV, Byes RS, et al. The safety and efficacy of intrathecal opioid analgesia for acute postoperative pain: seven years' experience with 5969 surgical patients at Indiana University Hospital. Anesth Analg 1999; 88: 599-604.

19 Scammell SJ. Apnoea with intrathecal morphine (Letter). Anaesth Intensive Care 2000; 28: 708.

20 Sarma VJ, Bostrom UV. Intrathecal morphine for the relief of post-hysterectomy pain - a double-blind, doseresponse study. Acta Anaesthesiol Scand 1993; 37: 223-7. 